\title{
Impaction of a Foreign Body in the Rectum by Improper Use of a (Electronic) Massager: A Case Report
}

\author{
Eun-Joo Jung, Chun-Geun Ryu, Gangmi Kim, Dae-Yong Hwang \\ Colorectal Cancer Center, Department of Surgery, Konkuk University Medical Center, Konkuk University School of Medicine, Seoul, Korea
}

\begin{abstract}
A male, 67 years old, visited the emergency room because of a foreign body impacted in his rectum. While he was being treated for grade-II hemorrhoids conservatively, he heard that massage of the peri-anal area could be helpful for preventing hemorrhoids. Thus, while using an electronic massager after placing the head of the machine into a short round bar, the head became separated from the machine, and this was inserted into the anus and impacted. The patient had anal discomfort without abdominal pain. His vital signs were stable, and no abnormal physical findings were found for the abdomen. On digital rectal examination, the rim of the foreign body was palpated about $8 \mathrm{~cm}$ from the anal verge. Anal bleeding, abnormal discharge, or foul odor was not found. On a simple abdominal X-ray, a radio-opaque foreign body was observed in the pelvic cavity, and mild leukocytosis was noted on the laboratory test. To avoid injury to the anal sphincter, we tried to remove the foreign body under the spinal anesthesia. After anesthesia had been administered, the foreign body was palpated more distally at 5-6 $\mathrm{cm}$ from the anal verge by digital examination, and the foreign body was found to have a hole in its center. This was held using a Kelly clamp, and with digital guiding, was removed through the anus. After removal, an anoscopic examination was performed to determine if mucosal injury had occurred in the rectum or anal canal. The patient was discharged without complication after 24 hours of close observation.
\end{abstract}

Keywords: Foreign bodies; Rectum; Massager; Electrical equipment

\section{INTRODUCTION}

A foreign body inside the anorectal tract is an intermittent situation a surgeon may encounter with a variety foreign bodies, input pathways, and clinical patterns. As a treatment, foreign body removal through a per-anum approach is considered to be the best way. However, a proctocolectomy or an enterostomy through a laparotomy might be necessary in cases where the foreign body cannot be removed through the rectum or in

Received: April 5, 2010 Accepted: June 14, 2010

Correspondence to: Dae-Yong Hwang, M.D.

Colorectal Cancer Center, Department of Surgery, Konkuk University Medical

Center, 4-12 Hwayang-dong, Gwangjin-gu, Seoul 143-729, Korea

Tel: +82-2-2030-5111, Fax: +82-2-2030-5112

E-mail: hwangcrc@kuh.ac.kr

This case was presented on 61th annual congress of the Korean surgical society, 2008.

(C) 2010 The Korean Society of Coloproctology

This is an open-access article distributed under the terms of the Creative Commons Attribution NonCommercial License (http://creativecommons.org/licenses/by-nc/3.0) which permits unrestricted noncommercial use, distribution, and reproduction in any medium, provided the original work is properly cited. cases with associated anorectal injury. We report one case of a rectal foreign body that was caused by the inattentive usage of a common instrument; the foreign body was removed transanally.

\section{CASE REPORT}

The patient was a 67 -year-old male who had inserted a foreign body into his rectum 7 hours before the hospitalization at the Emergency Room (ER). The patient had a second-degree hemorrhoid and was undergoing conservative treatment. $\mathrm{He}$ heard that a hemorrhoid could be improved if he used a massager to massage around the anal area. The patient massaged the perianal area with a massager to which differently shaped tips could be attached. The tip was unintentionally separated from the massager body inside the patient's rectum. The patient tried to remove the tip by himself, but came to the ER after feeling the foreign body move inside.

His past medical history showed a right hemicolectomy 2.5 years earlier because of ascending colon cancer. According to the pathologic results at that time, adjuvant chemotherapy was 
not performed because of the tumor was T2N0M0, stage Ib. He was going through a periodic follow-up and did not have any other significant medical history.

The patient did not have abdominal pain, but felt discomfort and minor pain around the perianal area. The patient's vital signs were stable, with a pulse rate of 70 per minute, a respiratory rate of 12 per minute, a blood pressure of $130 / 80 \mathrm{mmHg}$, and a temperature of $36.5^{\circ} \mathrm{C}$. According to the physical examination, the abdomen was soft and flat, the bowel sound was normal, and no abdominal pain was being experienced. Upon digital rectal examination, the distal edge of the foreign body, which was located approximately $8 \mathrm{~cm}$ from the anal verge, was

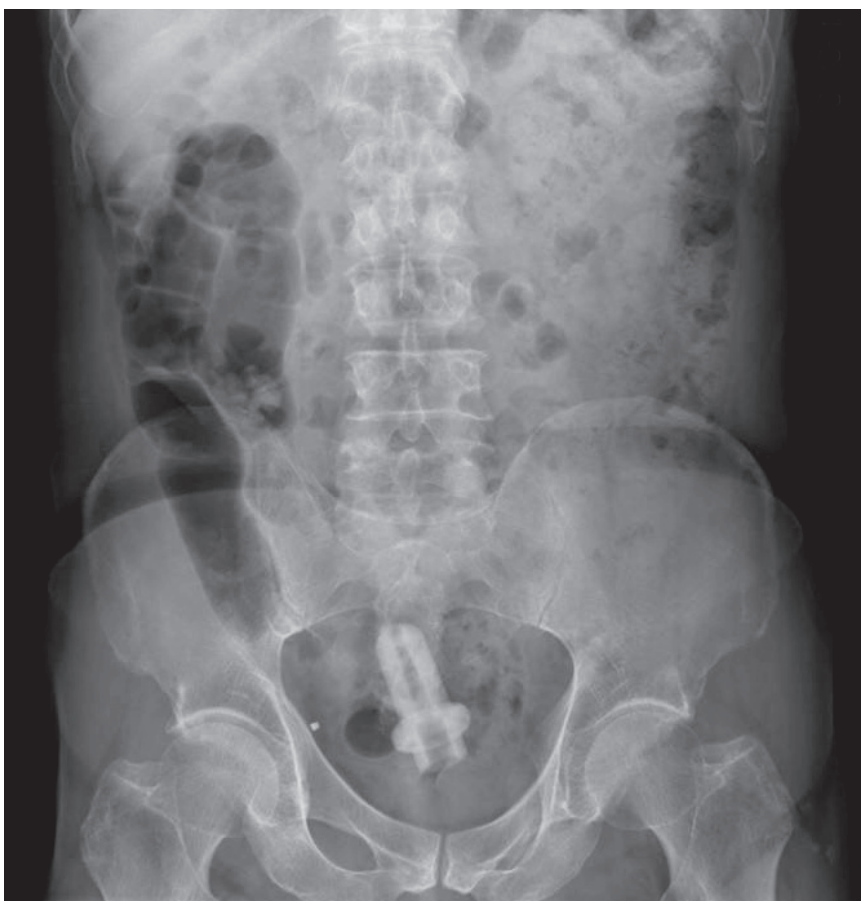

Fig. 1. Simple abdominal X-ray taken in an Emergency Room.
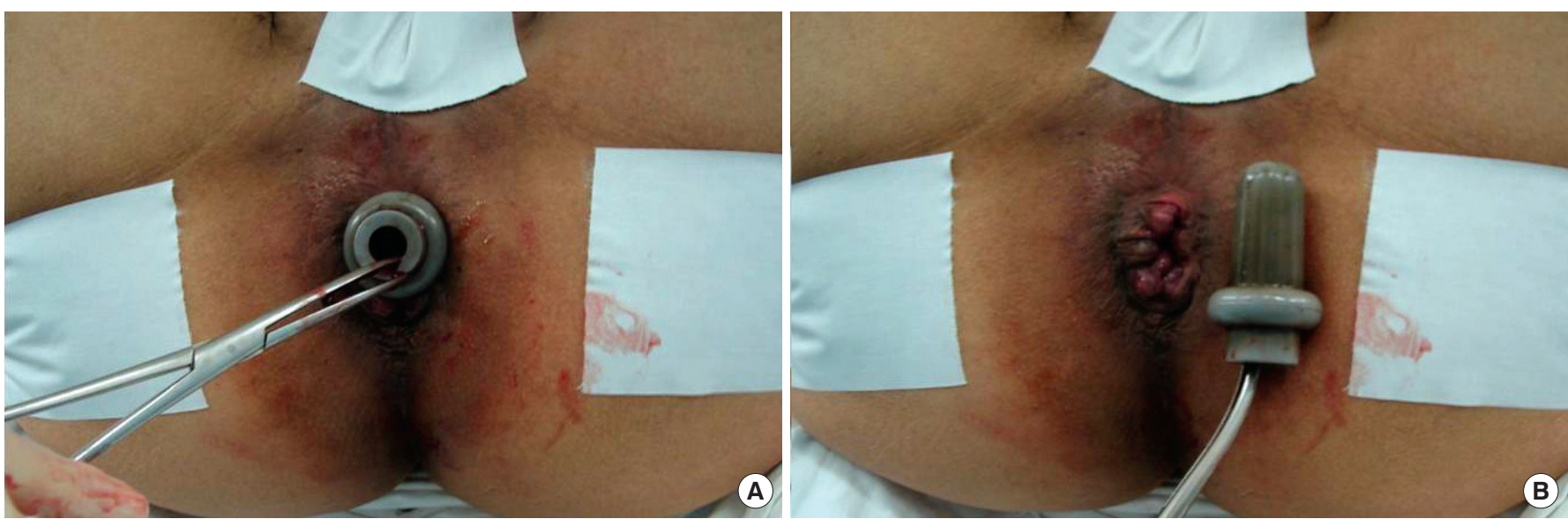

palpable. The foreign body was hard and had a smooth surface. There were no blood, no tar-colored rectum discharge, and no foul odor.

On a simple abdominal X-ray image, the foreign body was observed to be a radio-opaque object located in the pelvic cavity (Fig. 1). According to the laboratory test, the white blood cell count was $10,440 / \mu \mathrm{L}$ (neutrophils, $84 \%$; normal range, $8,770 /$ $\mu \mathrm{L})$, which showed an increase in white blood cell count and neutrophil count. There were no other abnormalities on the blood test.

Since there was a possibility of anal sphincter damage if the foreign body was removed at the ER, removal after anesthesia was decided upon. After spinal anesthesia, a digital rectal examination was done in the lithotomy position. Unlike the first digital rectal examination in the ER, the object moving a bit distally was located 5-6 cm from the anal verge. With careful palpation so as not to move the object inside, a hole could be felt in the center of the foreign body, and a Kelly forcep was used to hold the object and to remove it from the rectum (Fig. 2). The surgery was finished after using anoscopy to check for mu-

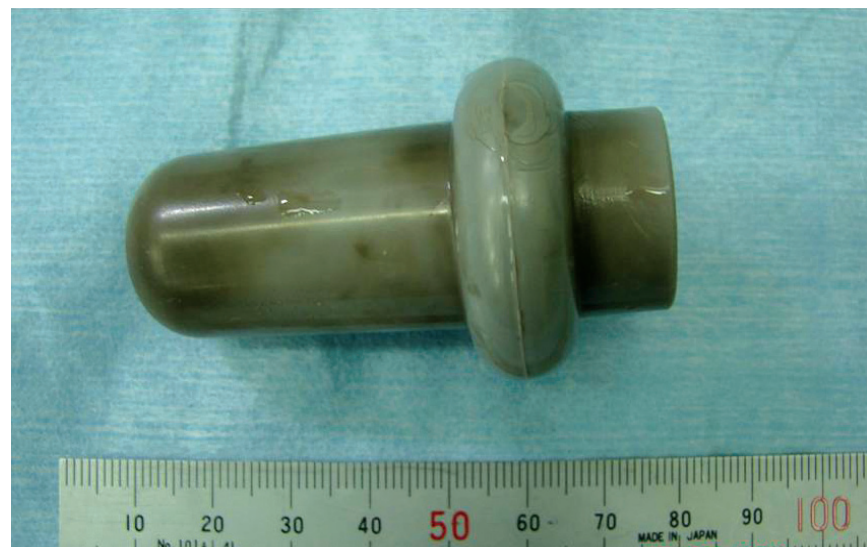

Fig. 3. Removed foreign body.

Fig. 2. (A) Removal of the foreign body. (B) Immediately after removal of the foreign body. 
cosal damage on the distal rectum and the anal canal.

The removed foreign body was a gray-colored hard-rubberbased object which was $7 \mathrm{~cm}$ long and $3 \mathrm{~m}$ in diameter (Fig. 3). After making sure that there were no anal bleeding and no abnormality on the physical examination of the abdomen for 24 hours, the patient was discharged. Currently, he is undergoing periodic follow up for colon cancer.

\section{DISCUSSION}

A foreign body inside the anorectal area has various causes, and the treatment method is selected based on the cause, the symptoms, and the severity of anorectal damage [1-3]. The type of foreign body varies with the pathway for insertion. Peroral foreign bodies are usually animal bones, fish bones, fish hooks, or tooth picks that have been swallowed by patients who are inattentive or drunken [1]. In patients with mental illnesses, numerous unexpected foreign bodies are reported $[1,2]$. In cases where the foreign body was inserted through the anus, a sexual purpose is reported to be the most common cause [2, 4-7]. Some references even reported that more than $50 \%$ of the cases were caused by insertion for sexual purposes $[6,7]$. The types of foreign bodies inserted through the rectum are very diverse, and numerous references reported these different kinds of objects: for example, vegetables (cucumbers or eggplants), light bulbs, glass bottles, liquor shot glasses, water glasses, pistols, candles, toothbrushes, portable heaters, soda cans, shoehorns, brooms, umbrellas, rocks, magazines, thermometers, sex toys, vibrators and so on [1-3, 6-10]. There are regional differences. In eastern countries, including Korea and Japan, where raw fish and grilled fish are often consumed, the rate of perorally-inserted foreign bodies is reported to be high [1]. However, in western countries, foreign-body insertion through the anus for sexual pleasure is more common $[1,4,10]$.

In most cases, the best treatment is transanal removal of the foreign body. It is known that approximately $74 \%$ of the patients can be treated in the ER; ie, the foreign body can be removed transanally in the ER [11]. However, if the patients do not cooperate due to discomfort or pain during the procedure, repetitive attempts to removing the foreign body may be necessary. This might result in the object being shifted deeper into the anal canal or in anal sphincter damage [12]. In such cases, it is better to approach per anum after anesthesia rather than continuing the repetitive attempts to remove the object. In cases where the foreign body is very large or complications (rectal perforation or peritonitis) are found, a proctocolectomy or an enterostomy through a laparotomy might be necessary $[1,4]$.

In patients such as the one in this case report where the foreign body is located lower than the rectosigmoid junction, spinal or pudendum anesthesia is the most appropriate. This relaxes the pelvic floor muscle and allows the patient to increase the abdominal pressure at the appropriate moment, which helps move the foreign body towards the anus [12]. In addition, the lithotomy position is preferred when surgically removing a foreign body because when the foreign body is located in the upper or mid rectum, using gravity to guide the object along a line parallel to the sacral curve is easier in the lithotomy position than in the Jackknife prone position or the left lateral position. It is also more convenient for compressing the abdomen during the operation [12]. After removal of the foreign body, the patient should be observed for 1 or 2 days in case of complications such as delayed damage caused by the foreign body $[6,9,12]$.

After experiencing this case, we collected brief information about massagers. Massagers are commonly used in daily life to relax the muscle tension. About 20 different massagers from 15 or more producers are on sale according to our internet web search. Five of them were manufactured to accommodate differently-shaped alterable heads to support a more effective massage to different parts of the human body on instruction. The tip of the massager that this patient had used was included in two kinds of massagers that were on sale. This case report shows that users of massagers need to pay close attention to the dangers associated with inattentive usage.

\section{CONFLICT OF INTEREST}

No potential conflict of interest relevant to this article was reported.

\section{REFERENCES}

1. Choi KD. Foreign bodies in the anorectum: report of five cases and a review of literature. J Korean Soc Coloproctol 1990;6:55-62.

2. Clarke DL, Buccimazza I, Anderson FA, Thomson SR. Colorectal foreign bodies. Colorectal Dis 2005;7:98-103.

3. Yaman M, Deitel M, Burul CJ, Shahi B, Hadar B. Foreign bodies in the rectum. Can J Surg. 1993;36:173-7.

4. Huang WC, Jiang JK, Wang HS, Yang SH, Chen WS, Lin TC, et al. Retained rectal foreign bodies. J Chin Med Assoc 2003;66: 607-12.

5. Lake JP, Essani R, Petrone P, Kaiser AM, Asensio J, Beart RW Jr. Management of retained colorectal foreign bodies: predictors of operative intervention. Dis Colon Rectum 2004;47:1694-8.

6. Cohen JS, Sackier JM. Management of colorectal foreign bodies. J R Coll Surg Edinb 1996;41:312-5.

7. Yacobi Y, Tsivian A, Sidi AA. Emergent and surgical interventions for injuries associated with eroticism: a review. J Trauma 2007;62: 1522-30.

8. Coulson CJ, Brammer RD, Stonelake PS. Extraction of a rectal foreign body using an electromagnet. Int J Colorectal Dis 2005; 20:194-5.

9. Kouraklis G, Misiakos E, Dovas N, Karatzas G, Gogas J. Management of foreign bodies of the rectum: report of 21 cases. J R Coll 
Surg Edinb 1997;42:246-7.

10. Rodriguez-Hermosa JI, Codina-Cazador A, Ruiz B, Sirvent JM, Roig J, Farres R. Management of foreign bodies in the rectum. Colorectal Dis 2007;9:543-8.

11. Berghoff KR, Franklin ME Jr. Laparoscopic-assisted rectal for- eign body removal: report of a case. Dis Colon Rectum 2005;48: 1975-7.

12. Goldberg JE, Steele SR. Rectal foreign bodies. Surg Clin North Am 2010;90:173-84. 